\title{
Primary health care seeking behaviour of people with physical disabilities in Bangladesh: a cross-sectional study
}

\author{
Jhalok Ronjan Talukdar ${ }^{1,2^{*}}$ (D), Ilias Mahmud ${ }^{1,3}$ and Sabina Faiz Rashid ${ }^{1}$
}

\begin{abstract}
Background: People with disabilities constitute about 10\% of the total population of Bangladesh. They are more likely to experience poor health than those without disabilities. However, there is a lack of evidence on their primary health care (PHC) seeking behaviour for their general illness. The aim of this study was to understand the PHC seeking behaviour of people with physical disabilities (PWPDs), and to investigate the determinants of such behaviours.
\end{abstract}

Methods: We surveyed 282 PWPDs, aged $\geq 18$ years, using a structured questionnaire. Participants were recruited from the out-patient department of a rehabilitation centre in Dhaka between November and December 2014. We explored PHC seeking behaviour using frequency distribution. We performed logistic regression to investigate the factors that determined their PHC seeking behaviours for general illness. In our logistic regression model, the outcome variable was whether PWPDs received treatment from a formal health care provider. The predictors were socio-demographic characteristics and clinical characteristics such as type of impairment and type of illness experienced.

Results: Among 282 participants, 85\% suffered from general illness in the past 6 months. The participants in the higher age group, for example, age group 31-45 years ( $\mathrm{OR}=3.9$, [95\% $\mathrm{Cl} 1.2$ to 13.4$]), 46-59$ years $(\mathrm{OR}=13.6,[95 \% \mathrm{Cl} 2$. 9 to 63.7) and $60+$ years $(\mathrm{OR}=12.5,[95 \% \mathrm{Cl} 1.7$ to 93.0]) were more likely to seek treatment from formal health care providers than the age group 18-30 years. The educational attainment of the primary income earning family member $(\mathrm{OR}=3.2$, [Cl 1.1 to 9.6]), religion $(\mathrm{OR}=0.3,[95 \% \mathrm{Cl} 0.1$ to 0.98$])$ and mobility aid used (OR=4.0, [95\% Cl 1.2 to 13$]$ ) were determinants for seeking health care from a formal health care provider. Moreover, the type of illness suffered by participant was a strong predictor of their decision to seek treatment from a formal health care provider. The participants who suffered from urinary tract infections $(\mathrm{OR}=10.3,[95 \% \mathrm{Cl} 2.3$ to 46.6$])$, ulcers $(\mathrm{OR}=13.1$, [95\% Cl 2.11 to 79.3$])$ and pain ( $\mathrm{OR}=3.6$, [95\% Cl 1.4 to 9.4]) were more likely to seek treatment from formal health care provider than who suffered from fever.

Conclusions: Age, religion, earning member's education, type of mobility aids used and type of illness suffered were explicative determinants of PHC seeking behaviour of PWPDs. The results suggest that these factors should be considered when devising interventions for this population. Moreover, accessibility, quality of care and expertise of the providers in treating disabled people were among the other factors reported by PWPDs which influence their decision to seek health care. In order to provide inclusive health services, primary health centres need to consider these determinants.

Keywords: Disability, Physical disability, Person with physical disabilities, Health care seeking behaviour, Factors of primary health care seeking behaviour

\footnotetext{
* Correspondence: jhalok01@gmail.com

${ }^{1}$ BRAC James P Grant School of Public Health, BRAC University, Dhaka,

Bangladesh

${ }^{2}$ Department of Health Research Methods, Evidence, and Impact, McMaster

University, Hamilton, ON, Canada

Full list of author information is available at the end of the article
}

(c) The Author(s). 2018 Open Access This article is distributed under the terms of the Creative Commons Attribution 4.0 International License (http://creativecommons.org/licenses/by/4.0/), which permits unrestricted use, distribution, and reproduction in any medium, provided you give appropriate credit to the original author(s) and the source, provide a link to the Creative Commons license, and indicate if changes were made. The Creative Commons Public Domain Dedication waiver (http://creativecommons.org/publicdomain/zero/1.0/) applies to the data made available in this article, unless otherwise stated. 


\section{Background}

Disability is the negative outcome of a complex interaction between an individual's health conditions and his/ her personal, environmental and social contexts $[1,2]$. This negative interaction results in limitations in performing activities and restrictions in participation in life situations. We defined physical disability as an umbrella term of physical impairment, activity limitations and participation restrictions $[1,3]$.

Globally more than one billion people are living with some form of disability, and around 110 to 190 million adults are experiencing difficulties in performing everyday activities and participating in life situations [4]. Currently, we are observing an increase in the size of the aging population and a shift of in the global burden of diseases from communicable to non-communicable diseases. As a result, the number of people with disabilities is increasing globally [4].

Although the number of people with physical disabilities (PWPDs) is undoubtedly large and increasing globally [4], there is a lack of primary health care services sensitive to the special needs of PWPDs and they are rarely targeted by preventive health care services or health promotion activities tailored to their needs [5]. A number of factors such as prohibitive cost and limited availability of health care services, physical barriers to visiting health care facilities, inadequate knowledge and skills on the part of health care providers and perceived discrimination have a negative impact on PWPDs and prevent them from seeking health care [6-8]. Socio-demographic characteristics such as age, socio-economic status, education and place of residence also have a strong influence on health care seeking behaviour of PWPDs [8, 9]. Moreover, perceived discrimination also play an important role on health care seeking behaviour of PWPDs [10].

People with disabilities are more likely to suffer from health conditions requiring primary health care services than people without disabilities. Bangladesh has a high prevalence of disability. The Bangladesh Bureau of Statistics (BBS) [11] estimated the prevalence of disability in Bangladesh at $9.07 \%$ for male and $10 \%$ for female. A study by Titumir and Hossain [12] found that among the individuals living with disability in Bangladesh, $27.8 \%$ have physical impairment and $10.7 \%$ have multiple impairments. Therefore, the number of people with physical disabilities is believed to be very high, given the country has around 158 million people [13]. However, there is a lack of research evidence related to primary health care seeking behaviour of PWPDs in Bangladesh. Few studies [1417] were conducted in Bangladesh to explore the health care seeking behaviour of PWPDs for the treatment and rehabilitation of their disabling health condition but no such studies were conducted related to the primary health care seeking behaviour of PWPDs.

Knowledge of health care seeking behaviour is helpful in identifying available health services and assessing utilization of these services by the community. This knowledge can also be used to promote positive changes in health care seeking behaviour of the target population [18]. Improving access to quality health care can prevent the decline in income frequently caused by ill health [19]. To ensure the effectiveness of health interventions for PWPDs, it is necessary to ensure the participation of PWPDs. In this regard it is important to understand the needs and priorities of PWPDs related to their general health. Proper understanding of health care seeking behaviour for general illness and the factors determining health care seeking behaviour will help policy makers to design effective public health interventions in a way that will ensure participation of PWPDs. Moreover, this information will help policy makers to minimize the barriers to health care seeking behaviours. For example, if accessibility in health care settings is a major barrier to seeking health care by PWPDs in Bangladesh, then policy makers might try to understand what the current accessibility options are and what could be done to improve accessibility for PWPDs. If the issue is a lack of access to certain medical and rehabilitation professionals in the health care settings, then they might try to understand what specialized medical and rehabilitation professionals are required by PWPDs and make them available in health care settings. Understanding these barriers will help policy makers to take the proper measures so that PWPDs do not perceive or experience barriers to seeking health care.

The objective of the study was to describe the prevalence of primary health care seeking by PWPDs and to identify the determinants of the health care seeking behaviour of PWPDs for their general illness. This study will fill a gap in research regarding the health care seeking behaviour of PWPDs for their general illness, apart from disabling health condition. It will inform the development of primary health care interventions for PWPDs in Bangladesh.

\section{Methods \\ Study design}

This was a cross-sectional study carried out at the Centre for the Rehabilitation of the Paralysed (CRP), Dhaka, Bangladesh.

\section{Study setting}

CRP is a specialized treatment and rehabilitation centre for PWPDs in Bangladesh. It is located approximately $24 \mathrm{~km}$ northwest of Dhaka. CRP was selected as our study site as it 
is the largest tertiary care facility for PWPDs in Bangladesh. PWPDs from all over Bangladesh visit this centre for treatment and rehabilitation (http://www.crp-bangladesh.org/).

\section{Conceptual model}

This study was guided by an adaptation of Anderson's behavioural model of health services (as cited in [19]) which organizes all the factors that predict health care seeking behaviour into three broad categories - need factors, enabling factors and predisposing factors. 'Need factors' include the individual's perception of the severity of their health problems. 'Enabling factors' include factors such as affordability and availability of services and social network support. 'Predisposing factors' include individual characteristics such as age, sex, education, occupation, attitudes and beliefs regarding health care services and use of these services. We operationalized 'need' as the PWPDs' perceptions of the severity of their health problems which can be dealt at the primary health care other than the condition which contributed in physical disability. We considered the financial condition of the participants to be 'enabling factors'. We considered socio-demographic characteristics and individuals' perceptions regarding health care seeking behaviour for a specific illness to be 'predisposing factors'.

\section{Study participants}

The participants of the study were all PWPDs age 18 years or older who were visiting the CRP between November and December 2014 for physiotherapy or occupational therapy for their disabling health condition and met our predefined inclusion criteria. We included those participants who were living in their community with their physical disability for at least the past 6 consecutive months. We excluded those PWPDs who experienced a medical emergency or needed inpatient rehabilitation while receiving care at CRP.

\section{Sampling technique}

We employed a convenience sampling technique and included those PWPDs consecutively who sought treatment at the CRP during the study period.

\section{Data collection}

We used a structured interviewer administered questionnaire for data collection. In order to ensure the reliability and validity of data, we developed the questionnaire based on literature review. Two disability rehabilitation professionals then reviewed the questionnaire. Finally, it went through field testing and was revised accordingly. The first author and three data collectors interviewed all respondents. They received a two-day training on administering the questionnaire and potential ethical issues led by the senior researchers.

\section{Dependent and independent variables}

The independent variables for this study were participants' age, gender, religion, educational attainment, occupation, individual and household monthly income, form of impairment, types of mobility aids used, area of residence and type of illness suffered during the past 6 months. In addition, relationship with key earning member, household key earning members' educational attainment and occupation were used as independent variables.

Participants' age was originally recorded in completed years, but later recoded into four groups: 18-30 years, $31-45$ years, 46-59 years and 60 years or above. Educational attainment was classified into the following educational groups, based on the highest level completed: less than primary education, primary education, lower secondary education, upper secondary education and post-secondary or above. Occupation was classified into the following groups- elementary occupation (included agricultural, industrial and day labourers), government employees, non-government organization (NGO) or private employees (included clerical staff, mangers, teachers and professionals), students (studying in formal institutions), homemakers (individuals managing household/ family activities) and unemployed. Participants were classified into the following three impairment groups: paraplegia or tetraplegia, hemiplegia, and others which included any conditions affected a single arm or leg. Income was reported in Bangladeshi Taka (BDT) which was converted to US dollar (USD) and respondents were divided into two income groups: below median income level and median income level or above. The dependent variable was whether the PWPDs received treatment from formal health care providers.

\section{Data analysis}

Data were analysed using Stata/MP 13.0. Descriptive analyses were done to explore participants' socio-demographic and disability profile, primary health care seeking behaviour and the factors that shaped these behaviours. Bivariate analysis was done to understand the factors associated with seeking health care from formal health care provider. The associations between dependent and independent variables were investigated using Pearson chi-square or Fisher's exact tests.

Multivariate analysis was done to explain the health care seeking behaviour of PWPDs. In this case, a logistic regression model was developed to investigate the determinants for seeking treatment from a formal health care provider. This model is based on the purposeful selection of variables. In this case, besides the variables which demonstrated significant associations in bivariate analyses, some important variables were also added in the final model which were not significant in bivariate 
analyses but might be important if they were used with significant variables in the same model. Then specification error was checked to understand whether the model included the important independent variables and that none were excluded. The goodness-of-fit test suggested by Hosmer and Lemeshow was checked. The reported large $p$-values $(p=0.63)$ of the test were an indication that the data fit the model very well. Moreover, the multicollinearity of the final model was checked using variance inflation factor (VIF) and tolerance (which is $1 /$ VIF). If VIF is greater than 10 or tolerance is less than 0.1 for any variable, then these variables need further investigation. However, for the final model the VIF for all variables was around 1 which was an indication that there was no multicollinearity problem in this model.

\section{Results}

\section{Socio-demographic profile of the participants}

In total, 282 participants were included in the data analysis. Among the 282 participants, over two fifths (43\%) were 18 to 30 years old and majority currently married (63\%). About $28 \%$ of the participants had only completed primary education and more than half (61\%) of them did not have an economically productive occupation (Table 1).

In more than a third case (36\%) the participant him/ herself was the main earning member of the household. About 35\% of the main earning member had not completed primary education and $83 \%$ of main earning members were engaged in an economically productive occupation. About $70 \%$ of the households had less than or equal to five members and more than half of them had monthly income of more than 145 USD. The majority $(60 \%)$ of participants were living in urban areas.

\section{Physical impairment of participants}

The most common impairment experienced by participants was paraplegia/tetraplegia (44\%), and 49\% of participants in this group used a wheelchair. About $89 \%$ of the participants had an acquired disability versus 11\% who lived with a congenital disability. Most of the participants (57\%) had lived with this disability for more than 2 years.

\section{Primary health care seeking behaviour of PWPDs}

Of the 282 study participants, 239 suffered from different forms of general illness, apart from their disabling condition, that can be dealt in the primary health care centres in Bangladesh, in the last 6 months. The participants mostly suffered from fever, pain and infection (34, 22 and 17\% respectively). Among those who experienced a general illness, $88 \%$ of them took some form of treatment. Of those participants who took treatment, $55 \%$ of them took it within one day.
Some participants delayed treatment, that is they waited more than 3 days after onset of the symptoms to seek the treatment. The majority of these participants (35\%) faced mobility related barriers to access treatment services because they needed help from others to visit the health care facilities.

More than two-thirds (69\%) of the health care providers they consulted for a general illness, were formal health care providers. The reasons the participants revealed for consulting a formal health care provider over an informal health care provider included specialized (96\%) and good quality (74\%) care, which they felt they could only get from a formal health care provider. Easy access $(63 \%)$ was another important factor that led them to seek treatment from a formal health care provider. Most participants visited a private clinic or hospital (32\%), government hospital (30\%) or NGO clinic or hospital (30\%) to consult a formal health care provider.

Among the participants who sought treatment from an informal health care provider (31\%), $17 \%$ of them obtained treatment from a pharmacy and 5\% used self-care treatments. About $20 \%$ of the participants consulted both formal and informal health care providers, 39\% of these participants mentioned that they took several different forms of treatment as they were desperate to get well quickly.

\section{Expectations that influence decisions to visit health facilities}

The participants who took at least one form of treatment considered several issues before visiting a health care facility. Among the 239 participants who sought any form of treatment from any health facility, $82 \%$ of them prioritized choosing a health facility where they felt they would receive quality treatment. An equal number of participants (56\% each) expected specialized care and good communication when visiting a health facility. These factors were followed by good behaviour of health care provider (51\%) and access to the facility through mobility aid (45\%), as important factors influencing their decision to seek treatment from a heath facility. Participants could select more than one response; therefore the sum of the percentages is greater than $100 \%$.

\section{Determinants of treatment seeking from formal or informal health care providers}

Seeking treatment from formal or informal health care providers was examined with a logistic regression model including all independent variables. The diagnosis of this logistic model is explained in detail in the analysis section of this article. This model helped us to identify the independent variables which have significant statistical explicative power about treatment seeking for general 
Table 1 Socio-demographic profile of the participants, a crosssectional study of primary health care seeking behaviour of adults with physical disabilities in Bangladesh, November-December 2014

\begin{tabular}{ll}
\hline Variables & Frequency (\%) \\
\hline
\end{tabular}

Age (years)

$120(43)$

$18-30$

$96(34)$

$31-45$

45 (16)

60-80

Sex

Male

$21(7)$

Female

$237(84)$

Religion

Muslim

Hindu

$45(16)$

$259(92)$

23(8)

Educational attainment

Less than primary education

$76(27)$

Primary education

78 (28)

Lower secondary education

$43(15)$

Upper secondary education

Post-secondary or above

Occupation

Elementary occupation

Government, NGO or private employee

Small business

Student

Homemaker

Unemployed

Mean monthly income (USD)

Individual

Household $(\mathrm{HH})$

Form of impairment

Paraplegia/tetraplegia

Hemiplegia

Others

$43(15)$

$42(15)$

18 (6)

37 (13)

$54(19)$

$42(15)$

$23(8)$

108 (38)

77

265

$123(44)$

50 (18)

$109(39)$

Type of mobility aids used

Wheel chair

Crutch or stick

No mobility aid

Area of residence

Urban

Rural

Last illness suffered

UTI

Sores/ulcers

Fever

$82(34)$
Table 1 Socio-demographic profile of the participants, a crosssectional study of primary health care seeking behaviour of adults with physical disabilities in Bangladesh, November-December 2014 (Continued)

\begin{tabular}{ll}
\hline Variables & Frequency (\%) \\
\hline Pain & $52(22)$ \\
Diarrhea & $17(7)$ \\
Others & $47(20)$ \\
Key earning member in the HH & \\
Participant & $101(36)$ \\
Father or Mother & $77(27)$ \\
Brother or Sister & $31(11)$ \\
Wife & $39(14)$ \\
Others & $34(12)$ \\
HH key Earner's educational attainment & \\
Less than primary education & $98(35)$ \\
Primary education & $69(24)$ \\
Lower secondary education & $31(11)$ \\
Upper secondary education & $37(13)$ \\
Post-secondary or above & $47(17)$ \\
HH key earner's occupation & \\
Elementary occupation & $45(16)$ \\
Government, NGO or private employees & $80(28)$ \\
Business & $109(39)$ \\
Unemployed & $48(17)$ \\
\hline
\end{tabular}

illness by PWPDs. The output of this logistic regression model is presented in Table 2 .

According to this model, participant's age, religion, earning member's education, mobility aid used and last illness suffered were statistically significant to explain seeking treatment from formal health care provider over informal health care provider for their general illness.

The model demonstrated that the older PWPDs were more likely to seek treatment from formal health care provider than younger PWPDs. It indicated that participants who were 31 to 45 years old, 46-59 years old and 60 years old or above, were more likely to seek treatment from formal health care provider than participants who were $18-30$ years old $(\mathrm{OR}=3.9$, [95\% CI 1.2 to 13.4]; $\mathrm{OR}=13.6$, [95\% CI 2.9 to 63.7] and $\mathrm{OR}=12.5$, [95\% CI 1.7 to 93.0] respectively). It also evident from this model that the Hindu PWPDs were less likely to seek treatment from formal health care provider than the Muslim PWPDs (OR=00.3, [95\% CI 0.1 to 0.98]). The education level of main earning member was also an important determinant for seeking treatment from formal health care providers. The PWPDs were more likely to seek treatment from formal health care providers when the main earning member had at least a 
Table 2 Multivariable logistic regression model predicting primary health care seeking for general illness from formal providers, a cross-sectional study of primary healthcare seeking behaviour of adults with physical disabilities in Bangladesh, November-December 2014

\begin{tabular}{lcl}
\hline Variables & Odds Ratio & $\begin{array}{l}95 \% \text { Conf. } \\
\text { Interval }\end{array}$ \\
\hline
\end{tabular}

Age

$18-30$

$31-45$

$46-59$

1.0

60 or over

3.9

13.6

Sex

\section{Male}

Female

Marital status

Ever married

Never Married

1.0

Religion

Muslim

Hindu

1.0

0.3

Educational Attainment

Less than primary

Primary education

Lower secondary education

Upper secondary education

Post-secondary or above

Occupation

Elementary
Government, NGO or private employees
Business
Student
Homemakers
Unemployed

Income

$\begin{array}{ll}\text { Lowest } & 1.0 \\ \text { Third } & \\ \text { Fourth } & 0.6 \\ \text { Highest } & 0.4\end{array}$

Relation to Key earning member in household $(\mathrm{HH})$

Self

1.0

Father or Mother

4.2

Brother or Sister

22.8

Wife

Others

0.4

Educational attainment- key earning member

Less than primary
Table 2 Multivariable logistic regression model predicting primary health care seeking for general illness from formal providers, a cross-sectional study of primary healthcare seeking behaviour of adults with physical disabilities in Bangladesh, November-December 2014 (Continued)

\begin{tabular}{|c|c|c|c|}
\hline \multirow{2}{*}{$\begin{array}{l}\text { Variables } \\
\text { Primary education }\end{array}$} & \multirow{2}{*}{$\begin{array}{l}\text { Odds Ratio } \\
3.2\end{array}$} & \multicolumn{2}{|c|}{$\begin{array}{l}\text { 95\% Conf. } \\
\text { Interval }\end{array}$} \\
\hline & & $(1.1$ & 9.6) \\
\hline Lower secondary education & 1.5 & $(0.4$ & $6.1)$ \\
\hline Upper secondary education & 3.0 & $(0.8$ & 11.5) \\
\hline Post-secondary or above & 1.4 & $(0.2$ & 7.5) \\
\hline \multicolumn{4}{|l|}{ Occupation-key earning member } \\
\hline Elementary & 1.0 & & \\
\hline Government, NGO or private employees & 0.6 & (0.1, & 2.6) \\
\hline Business & 1.2 & $(0.3$ & 4.3) \\
\hline Unemployed & 1.4 & $(0.3$ & 5.5) \\
\hline \multicolumn{4}{|l|}{ Household income } \\
\hline Second quintile & 1.0 & & \\
\hline Lowest & 1.5 & $(0.4$ & $66.4)$ \\
\hline Third & 0.6 & $(0.1$ & 3.0) \\
\hline Highest & 0.2 & $(0.0$ & 11.4) \\
\hline \multicolumn{4}{|l|}{ Area of residence } \\
\hline Urban & 1.0 & 5 & \\
\hline Rural & 0.8 & $(0.4$ & 1.9) \\
\hline \multicolumn{4}{|l|}{ Type of impairment } \\
\hline Paraplegia/tetraplegia & 1.0 & & \\
\hline Hemiplegia & 1.9 & (0.7, & $55.6)$ \\
\hline Others & 11.2 & $(0.4$ & 33.6) \\
\hline \multicolumn{4}{|l|}{ Mobility aid used } \\
\hline No mobility aid required & 1.0 & & \\
\hline Wheel chair & 4.0 & $(1.2$ & 122.9) \\
\hline Crutch or stick & 2.9 & $(0.8$ & $66.1)$ \\
\hline \multicolumn{4}{|l|}{ Last illness suffered } \\
\hline Fever & 1.0 & & \\
\hline Urinary tract infection & 10.3 & $(2.3$, & 46.6) \\
\hline Sores or ulcer & 1313.1 & (2.1, & 79.3) \\
\hline Pain & 3.6 & $(1.4$ & 99.4) \\
\hline Diarrhea & 3.3 & $(0.9$ & 12.6) \\
\hline Others & 0.8 & $(0.3$ & 2.0) \\
\hline
\end{tabular}

primary education in comparison with those that had less than a primary education $(\mathrm{OR}=3.2$, [95\% CI 1.1 to 9.6]). The model also indicates that the type of mobility aid used was an important predictor of decisions to seek treatment from a formal health care provider. The PWPDs who used wheelchairs were more likely to seek treatment from formal health care providers than those who did not use any mobility aid $(\mathrm{OR}=4.0$, [95\% CI 1.22 to 13]). Moreover, the illness suffered by PWPDs in 
the past 6 months was another determinant for seeking treatment from a formal health care provider. The PWPDs who suffered from urinary tract infections, sores or ulcers and pain were more likely to seek treatment from formal health care providers than those who suffered from fever $(\mathrm{OR}=10.3$, [CI 2.3 to 46.6], $\mathrm{OR}=13.1$, [95\% CI 2.11 to 79.3] and $\mathrm{OR}=3.6$, [95\% CI 1.4 to 9.4]). The sex of the PWPDs was marginally significant (OR = 4.7, [95\% CI 0.94 to 23.6] to predict the health care seeking behaviour of PWPDs.

\section{Discussion}

This study is the first of its kind in Bangladesh to collect data on primary health care seeking behaviour of PWPDs. A number of studies [14-17] were conducted to understand the health care seeking behaviour of disabled people for the treatment of their disability. However, this study describes the prevalence of PWPDs and identify the determinants of health care seeking behaviours of PWPDs for the treatment of their general illness, apart from their physical disability.

\section{Factors determining the health care seeking behaviour of PWPDs}

This study found that comparatively older individuals (31-45 years, 46-59 years and 60+years) were more likely to seek treatment from formal health care providers than the younger age group (18-30). Ahmed [19] also demonstrated similar results in his study. He found that older people are more likely to use allopath treatment from formal health care providers than younger people. In his study, the type of illness suffered during the last six months was also a major factor influencing whether participants sought treatment from formal health care providers. The current study demonstrated that participants who suffered from infection, ulcers and pain were more likely to seek treatment from formal health care provider than those who suffered from fever. The explanation could be that these illnesses require or perceived to require more specialized treatment from a formal health care provider in comparison with fever. As a result, PWPDs might visit a formal health care provider rather than an informal health care provider. Moreover, the study demonstrated that the PWPDs who used wheelchairs were more likely to seek treatment from formal health care providers. The explanation could be the same, that PWPDs who used wheelchairs might suffer more from infections and other severe illnesses because of the nature of their physical disability. PWPDs who use a wheelchair may generally require more specialized health care so they might seek treatment from a formal health care provider.

This study identified that fever, pain and infection were the most prevalent general illnesses suffered by the participants over the last six months. This finding is supported by the Bangladesh Household Income and Expenditure Survey [11] which identified ulcer and fever as the two most prevalent illnesses suffered by the general population. Another study [20] in Bangladesh concerning disease patterns and health care seeking behaviour of the general population also observed fever as the most common illness reported by the participants.

\section{Health care seeking behaviour of PWPDs}

The present study demonstrated that $88 \%$ of the participants took some form of treatment for their illness and the majority of those participants (69\%) took treatment from a formal health care provider. However, other studies $[16,19]$ have found that the majority of participants preferred to seek treatment from informal health care providers rather than formal health care providers. A study [21] looking at health care seeking behaviour among tribal people in Bangladesh found that participants preferred informal health care providers over formal health care providers because of the high cost associated with seeking treatment from formal health care providers. According to Cockcroft, Milne and Andersson [22], who conducted a study in Bangladesh about health service delivery, people choose informal health care providers over formal health care providers because the cost of visiting an informal health care provider is lower. The possible reasons for visiting formal health care providers by the current study participants might be that they are economically solvent (mean household income of the study participant was around 265 USD), compared to the study conducted by Hossain et al. [16], where around half of the participant's annual family income was less than 181 USD.

Since most of the participants (60\%) were living in urban areas, so it may have been easier for them to seek treatment in government hospitals or non-government organization (NGO) health care facilities where the cost is very low in comparison with private health care providers. This study supports this view because among participants who visited a formal health care provider, only $8 \%$ of them visited a private health care provider while $60 \%$, visited a government or NGO health care facilities.

Another important factor was that the participants mostly suffered from infection, pain, and fever. For infection and pain, participants might have felt that they needed treatment from formal health care provider. Among the participants who suffered from infection, all of them sought treatment from formal health care providers. It was also noticeable that when the participants were asked about important factors that influenced their decision to seek treatment from a health care provider, they mentioned good quality treatment and the 
availability of specialized care as important factors. If quality of treatment and specialized care were perceived to be characteristics of formal health care providers, these factors may have led participants to seek treatment from formal health care providers.

Another finding of this study was that when the participants were from a family which had 6 or more members they were more likely to seek treatment from formal health care providers than those from smaller families. The explanation might be that to see a formal health care provider, the participants needed to travel to a distant place for which they needed support from a family member. Larger families may have facilitated the necessary travel. Moreover, the mean household income of current study participants was around 265 USD. This amount was more than seven times higher than the poverty line set by World Bank [23]. Given their household income, participants in this study may have had adequate resources to seek treatment from formal health care providers rather than going to an informal health care provider.

\section{Limitations of the study}

This study was a descriptive quantitative cross-sectional study. As a result, the current study suffered from several limitations which are discussed below:

1. The main limitation of the study is that data were collected at a specialized health care facility for disabled people. The participants who visited or lived around CRP during the study period were selected for the study. This could lead to selection bias as the timing of data collection could exclude participants who were eligible for the study but were not available during the specific time of data collection. It was also not possible to cover a large number of participants within the short data collection period. Moreover, the people who visit this specialized health care facility are comparatively wealthy. Therefore, the experiences of these people might be different from those who are living in the community and who do not have the ability to visit a specialized health care facility for their treatment. To address this problem, we selected respondents who have lived in the community at least for 6 months and we retrospectively asked questions about their health care seeking behaviour before visiting CRP. Unfortunately, this cannot completely replicate a study conducted directly in the community.

2. If we had been able to select the participants using random sampling, it would have balanced the baseline characteristics, known and unknown, of the participants. However, this was not possible as there was no comprehensive patient list and the patients who visit the hospital were not fixed. Convenience samples cannot balance the baseline characteristics of the participants and may produce biased results. Moreover, it was not possible to collect data from a large number of people. Initially we calculated the sample size for the study using 95\% confidence level and the sample size was 384 . However, it was possible to collect data from only 282 participants. To address this problem, we recruited all available participants at that site during the study period; however, we failed to collect data from a representative sample which may have hampered the results.

3. This study was purely a quantitative study; however, we found that to more fully understand the health care seeking behaviour of participants, it was necessary to include some qualitative questions in our questionnaire. We identified that a mixed methods study would be appropriate for this research question. We tried to minimize this problem with literature review and field testing of the questionnaire. Based on the current study, a qualitative study could be conducted to explore certain types of health care seeking behaviours.

4. We collected data retrospectively from the participants to understand their health care seeking behaviour in the community. Some of the participants were living in CRP or in the community around CRP for several months as they received long term treatment for their illness. This might lead to recall bias which could influence the results of the study.

\section{Conclusions}

The study found participant's age, religion, type of mobility aids used, type of illness suffered, main earning member's education were associated with primary health care seeking behaviour of PWPDs. As a result, we suggest considering these determinants to devise primary health care interventions for the PWPDs. The study also found that easy access to health care facilities was one of the major factors PWPDs considered when choosing one health care facility over another. It is necessary to think about accessibility issues for PWPDs including building ramps so that the PWPDs can move within the health care facility without help from other people. Moreover, most of the PWPDs in this study visited formal health care providers as they needed specialized care for their general illness other than their disability. Therefore, we propose a primary health care intervention for PWPDs that considers accessibility issues and the need for health care providers who are sensitized to the special needs of PWPDs. 


\section{Abbreviations}

BBS: Bangladesh Bureau of Statistics; BDT: Bangladeshi Taka; CRP: Centre for the Rehabilitation of the Paralysed; ERC: Ethical Review Committee; JPGSPH: BRAC James P. Grant School of Public Health; NGO: NonGovernmental Organization; PWPDs: People with physical disabilities; SLP: Summative learning project; WHO: World Health Organization

\section{Acknowledgements}

This study is a part of JRT's MPH summative learning project (SLP) on primary health care of PWPDs. IM and SFR supervised this project. We appreciate the help we received from the Centre for the Rehabilitation of the Paralysed (CRP) during our data collection. The authors thankSaritaVerma, Masum al Jaki, Md. Shajjad Hossain, Peter Kaimenyi, Raia Azmi, Shamsun Nahar, Sifat Yusuf and Sushama Kanan for commenting on the study proposal and/or assisting in data collection. We are very grateful to Rachel Yantzi, Clinical Research Coordinator, Department of Pediatrics, McMaster University for offering her time to review the whole manuscript.

\section{Funding}

This study was funded by the BRAC James P Grant School of Public Health, Dhaka, Bangladesh.

\section{Availability of data and materials}

Data is available from the corresponding author on reasonable request from the reviewers.

\section{Authors' contributions}

IM and JRT conceptualized this study. JRT conducted the interviews, analyzed and interpreted the data with supervision from IM and SFR. JRT wrote the initial draft of the manuscript and revised the draft based on feedback received from IM and SFR. JRT and IM addressed reviewers' comments. All authors read and approved the final manuscript.

\section{Authors' information}

'JRT is a Senior Research Associate at BRAC James P Grant School of Public Health, BRAC University, Dhaka-1212, Bangladesh (on study leave) and currently an MSc in Health Research Methodology Candidate, McMaster University, Canada. IM is an Assistant Professor at BRAC James P Grant School of Public Health, BRAC University, Dhaka-1212, Bangladesh (on leave) and the College of Public Health and Health Informatics, Qassim University, Al Bukayriah, Al Qassim, Saudi Arabia. SFR is the Dean and Professor at BRAC James P Grant School of Public Health, BRAC University, Dhaka-1212, Bangladesh.

\section{Ethics approval and consent to participate}

Ethical approval for this study was obtained from the ethics review committee of the BRAC James P Grant School of Public Health, Dhaka, Bangladesh. In addition, permission for data collection was obtained from the CRP. Either written or verbal informed consent was obtained from the respondents. Verbal informed consent was obtained in cases of low literacy or when participants could not sign the consent form because of his/her impairment

\section{Consent for publication}

Not applicable.

\section{Competing interests}

The authors declare that they have no competing interests.

\section{Publisher's Note}

Springer Nature remains neutral with regard to jurisdictional claims in published maps and institutional affiliations.

\section{Author details}

'BRAC James P Grant School of Public Health, BRAC University, Dhaka, Bangladesh. ${ }^{2}$ Department of Health Research Methods, Evidence, and Impact, McMaster University, Hamilton, ON, Canada. ${ }^{3}$ College of Public Health \& Health Informatics, Qassim University, Bukayriah, Qassim, Kingdom of Saudi Arabia.
Received: 25 October 2017 Accepted: 21 June 2018

Published online: 03 September 2018

\section{References}

1. World Health Organization. International classification of functioning, disability and health: ICF. Geneva: World Health Organization; 2001.

2. Officer A, Groce NE. Key concepts in disability. Lancet. 2009;374(9704):1795.

3. Health Topics: Disabilities [http://www.who.int/topics/disabilities/en].

4. World Health Organization. World Report on Disability. Geneva, Switzerland: WHO; 2011.

5. Disability and health [http://www.who.int/mediacentre/factsheets/fs352/en]

6. Badu E, Agyei-Baffour P, Opoku MP. Access barriers to health care among people with disabilities in the Kumasi metropolis of Ghana. Canadian Journal of Disability Studies. 2016;5(2):131-51.

7. Senghor DB, Diop O, Sombie I. Analysis of the impact of healthcare support initiatives for physically disabled people on their access to care in the city of Saint-Louis, Senegal. BMC health services research. 2017;17(Suppl 2):695.

8. Eide AH, Mannan H, Khogali M, van Rooy G, Swartz L, Munthali A, Hem KG, MacLachlan M, Dyrstad K. Perceived barriers for accessing health services among individuals with disability in four African countries. PLoS One. 2015; 10(5):e0125915.

9. Yen SM, Kung PT, Tsai WC. Factors associated with free adult preventive health care utilization among physically disabled people in Taiwan: nationwide population-based study. BMC Health Serv Res. 2014;14:610.

10. Moscoso-Porras MG, Alvarado GF. Association between perceived discrimination and healthcare-seeking behavior in people with a disability. Disability and health journal. 2018;11(1):93-8.

11. Bangladesh Bureau of Statistics (BBS). Household Income and Expenditure Survey 2010. Government of Bangladesh: Dhaka, BBS, Planning Division, Ministry of Planning; 2011

12. Titumir RAM, Hossain J. Disability in Bangladesh: prevalence, knowledge, attitudes and practices. Dhaka: Unnayan Onneshan; 2005.

13. National Institute of Population Research Training, Mitra and Associates, ICF International. Bangladesh Demographic and Health Survey 2014. Dhaka, Bangladesh: NIPORT, Mitra and Associates, and ICF International; 2016.

14. Gudlavalleti MVS, John N, Allagh K, Sagar J, Kamalakannan S, Ramachandra SS. Access to health care and employment status of people with disabilities in South India, the SIDE (South India disability evidence) study. BMC Public Health. 2014;14(1):1125.

15. Mahmud I. Health seeking behaviour of disabled people in Bangladesh: Practices and determinants. Saarbrücken, Germany: LAMBERT Academic Publishing; 2011.

16. Hosain GM, Chatterjee N. Health-care utilization by disabled persons: a survey in rural Bangladesh. Disabil Rehabil. 1998;20(9):337-45.

17. Patel S. A multilevel exploration of treatment seeking behaviour of disabled persons in India. The Internet Journal of Tropical Medicine. 2007;5 Number 1, page number 1-7

18. Mackian S. A review of health seeking behaviour: problems and prospects. University of Manchester, Manchester, UK: Health Systems Development Programme; 2003.

19. Ahmed SM. Exploring health-seeking behaviour of disadvantaged populations in rural Bangladesh. Stockholm: Sweden: Karolinska University Press; 2005.

20. Rahman M, Islam M, Islam M, Sadhya G, Latif M. Disease pattern and health seeking behavior in rural Bangladesh. Faridpur Medical College Journal. 2011;6(1):32-7.

21. Rahman SA, Kielmann T, McPake B, Normand C. Healthcare-seeking behaviour among the tribal people of Bangladesh: can the current health system really meet their needs? J Health Popul Nutr. 2012;30(3):353-65.

22. Cockcroft A, Milne D, Andersson N. Bangladesh health and population sector Programme, 1998-2003: the third service delivery survey, 2003: final report. Dhaka: CIET Canada and ministry of health and family welfare: Government of the People's Republic of Bangladesh; 2004.

23. General Economics Division: Millennium Development Goals. Bangladesh Progress Report 2013. Dhaka: General Economics Division, Planning Commission, Government of the People's Republic of Bangladesh \& UNDP Bangladesh; 2014 